Chapter 8 (which comprises about one quarter of the book) is then devoted to the analysis of systems with bounded uncertainties. Firstly Horowitz' design method based on the Nichols chart is explained for SISO-problems. A thorough treatment of the effect of plant uncertainties in the general setting developed in Chapter 5 on closed-loop stability and performance of multivariable feedback systems follows. The uncertainties are characterized both by bounds on the norms and by bounds on the elements of the multivariable uncertain component of the overall plant in an input/output description, and both in the time domain and in the frequency domain. Finally, some results based on state-space models are outlined. One approach is to assume that the uncertainties only enter through the input matrix (i.e. they satisfy a matching condition). The case of interval matrices is discussed briefly with reference to Kharitonov's theorem.

The remaining chapters deal with design methods for uncertain plants based on these results. The Smith predictor is discussed and the principle that uncertainty limits the controller gain is explained. This motivates the subsequent derivation of design methods based on "low" gains where the controller action is restricted to low frequencies and hence the design can be based on a static plant model. The existence and the choice of stabilizing multivariable PI-controllers using only information about the static behaviour of the plant is treated in detail and demonstrated for several examples from industrial practice. Finally robust decentralized control is discussed with an emphasis on decentralized PI-controllers and a short introduction to the extension of Rosenbrock's direct Nyquist array method using the concept of generalized diagonal dominance.

Lunze's book covers a lot of material from the field of robust control. Its strong side is the comprehensive and unified presentation of the results on the analysis of systems with uncertainty. The design techniques discussed in the last chapters which are based on very little information about the plant dynamics and lead to multivariable PI-controllers are certainly useful in practical situations. However, I would have liked to see a little bit more on advanced design methods like $H_{\infty}$-sensitivity minimization, and also some sharper comments on the different results in the analysis part, especially since the book intends to "bridge the gap between the empirical ways in which practitioners have exploited the robustness of feedback systems and the powerful but sometimes abstractly formulated techniques that have been developed by theoreticians". For example the theorems in the analysis part show that the condition for robust stability in the fequency domain is of a pointwise nature, i.e. different conditions result at different frequencies if the uncertainty bound is not constant. On the contrary, in the time domain only a test which involves the integrals over the uncertainty bound and over a certain impulse response matrix of the nominal feedback system is available. Thus if the uncertainty bound is not uniform for all frequencies (as usually in practical cases), the analysis in the frequency domain provides much more detailed insight and should be more useful for design purposes.

As far as controller design is concerned, my opinion is that a useful general method must take the plant dynamics over an appropriate frequency range into account. Techniques which only use the static behaviour of the plant necessarily have to sacrifice bandwidth and hence performance, whereas approaches which require precise knowledge of the high-frequency dynamics are impractical in most cases. $H_{\infty}$-minimization is one approach to deal with robustness and performance simultaneously and exactly based on a model of the plant's dynamics. There is not yet a fully stringent manner how to use this approach to find a simple controller (e.g. of PI-type) for a plant with complex dynamics because the procedure itself provides controllers of very high order which must then be simplified. Also the selection of the weighting functions is a difficult issue, especially in the multivariable case. But even with my practitioner's hat on, I believe it to be an important step in the right direction.

A gap between the practical requirements and the insights provided by control theory will always exist-fortunately, because it is a major driving force in engineering science. The author has succeeded in building one bridge from theory to practical design techniques-we need more of them.

\section{About the reviewer}

Sebastian Engell was born in Düsseldorf in 1954. He received a diploma in electrical engineering from the Ruhruniversität Bochum in 1978. After one year with the Control Group of Professor H. Unbehauen in Bochum and the Control Systems Center at UMIST, Manchester, U.K., he joined the University of Duisburg as a research assistant where he worked on the relation of information theory and control with Professor $\mathrm{H}$. Schwarz. He received the Dr.-Ing. degree from the University of Duisburg in 1981. In 1982-1984 he worked as a postdoctoral researcher in Duisburg on real-time information theory and multivariable control. In 1984-1985 he was a visiting researcher at McGill University, Montreal. In 1986 he joined the Fraunhofer Institute for Information and Data Processing (IITB) in Karlsruhe where he then became head of the groups "Process Control" and "Control of Manufacturing Systems". In 1987 he obtained the "venia legendi" from the University of Duisburg where he was Privatdozent in the Department of Mechanical Engineering 1988-1990. Since August 1, 1990, he has been Professor for Process Control in the Department of Chemical Engineering at the University of Dortmund.

Professor Engell has authored and coauthored about 35 papers and one book in the areas of control systems design, real-time information theory with applications to control, and control of flexible manufacturing systems. He is currently chairman of the working group on control theory of the GMA, the German member society of IFAC.

\title{
Optimale Lineare Regelung*
}

\author{
S. Engell
}

Reviewer: HUIBERT KWAKERNAAK

University of Twente, P.O. Box 217, NL-7500 AE Enschede, The Netherlands.

THE ENGLISH translation of the title of this nice little book is Optimal Linear Control. The subtitle Grenzen der erreichbaren Regelgüte in linearen zeitinvarianten Regelkreisen

* Optimale Lineare Regelung by S. Engell. Vol. 18, Fachberichte Messen-Steuern-Regeln, herausgegeben von M. Syrbe und M. Thoma. Springer, Berlin (1988). ISBN 3-540-19120-8, DM 68
(Limits of achievable performance in linear time-invariant feedback control systems) is similar to that of a recent book by Boyd and Barratt (1990). Engell's book is qualitative where that of Boyd and Barratt is algorithmic, however.

Engell's book was originally written as a "Habilitationsschrift," a dissertation that in the German academic system qualifies the author for university teaching. Professor Isaac Horowitz once wrote, not even very long ago "Even the graduate $\mathrm{Ph} . \mathrm{D}$. often does not know the real reason why feedback is used in control" (Horowitz, 1982). Engell's book demonstrates that times have changed. The new generation of systems and control scientists know very well that 
feedback is essential for achieving stability, robustness and disturbance rejection. In depth studies of ideas and techniques initiated by Nyquist and Bode are common now. Engell belongs to this generation.

Optimale Lineare Regelung gives a neat exposition of important limitations of feedback. Using comparatively simple tools from complex function theory and techniques known from $\mathscr{H}_{\infty}$-optimal control the author explores questions such as the effect of the locations of poles and zeros on robustness and performance of linear feedback systems.

A nice feature of the book is that each chapter ends with a summary reviewing and evaluating the results. Just looking over these summaries is a rewarding experience and highly recommended, even for those for whom reading German is not a light task.

The contents of the book may be outlined as follows. Chapter 1 (Einleitung) introduces the problem setting and gives a historical background. Chapter 2 (Grundlagen für die Behandlung linearer zeitinvarianter Regelkreise im Frequenzbereich) presents the foundations for the analysis of linear feedback control systems in the frequency domain. Some techniques from complex function theory are reviewed, and various results on closed-loop stability are described.

Chapter 3 (Zur Spezifikation zeitkontinuierlicher Eingrößenregelkreise) discusses the specification of continuous-time single-input single-output feedback control systems. The closing summary clearly describes the three frequency regions (low, high and crossover) that are important in analyzing linear feedback systems.

Chapter 4 (Grundlegende Beschränkungen des erreichbaren Störfrequenzgangs) deals with the fundamental limitations for disturbance reduction. It relies on work of Zames and Francis (1983). In the summary illuminating statements may be found such as that the right half plane zero of the open-loop plant closest to the origin determines the largest achievable bandwidth, and that additional unstable poles make the situation worse, especially when the poles and zeros are close. The summary also indicates what types of practical systems are liable to have right half plane zeros.

Chapter 5 (Weitere grundlegende Beschränkungen der erreichbaren Regelgüte) presents further limitations for the achievable performance. The analysis concentrates on the complementary sensitivity function, whose minimal bandwidth is determined by the largest right half plane pole. Additional right half plane zeros complicate the situation further. An estimate is presented for the effect of deadtime.

Chapter 6 (Genauere Bestimmung der Erreichbaren Regelgüte für zeitkontinuierliche Eingrößensysteme mit Hilfe der Interpolationstheorie) is devoted to a more precise analysis of the achievable performance of single-inputsingle-output systems with interpolation theory. The results concern questions such as the effect on achievable performance of right half plane complex zero or pole pairs that are close to the imaginary or real axis.
Chapter 7 (Anwendungen von Tiefpaßfiltern mit Tschebycheff-Charakteristik zur Bestimmung der erreichbaren Regelgüte) describes the application of Chebychev filters for the solution of interpolation problems. Several examples illustrate the procedure.

Chapter 8 (Grenzen der erreichbaren Regelgüte in zeitdiskreten und Abtastregelkreisen) and Chapter 9 (Zur Übertragung der Ergebnisse auf Mehrgrößensysteme) discuss the extension of the results to discrete-time and sampled data systems on the one hand, and multivariable systems on the other. Important conclusions are that the analysis of sampled data systems between sampling times is quite complex but that otherwise the continuous-time results may be adapted, and that for multivariable systems a wealth of theory is available but much work remains to be done.

Engell's little book deserves to be published in English in a different series. Control theory researchers are well-advised to take notice of it. Teachers of control will find useful items to slip into their courses.

\section{References}

Boyd, S. P. and C. H. Barratt (1990). Linear Controller Design: Limits of Performance, Prentice-Hall, Englewood Cliffs.

Horowitz, I. (1982). Quantitative feedback theory. IEE Proc. 129, Pt. D, 215-226.

Zames, G. and B. A. Francis (1983). Feedback, minimax sensitivity, and optimal robustness. IEEE Trans. Aut. Control, AC-28, 585-601.

\section{About the reviewer}

Huibert Kwakernaak was born in 1937 in Rijswijk (Z.H), The Netherlands. He obtained the diploma in engineering physics at Delft University of Technology in 1960. Following this, he studied electrical engineering at the University of California at Berkeley, where he obtained the M.Sc. degree in 1962 and the Ph.D. degree in 1963.

After returning to The Netherlands Dr Kwakernaak was first a research associate and later a reader in the Departments of Engineering Physics and Mathematics of Delft University of Technology. Since 1970 he has been a full professor in the Department of Applied Mathematics of what is now the University of Twente.

Prof. Kwakernaak's interests are in linear control theory. $\mathrm{He}$ is the coauthor of several books (Linear Optimal Control Systems, with R. Sivan, Wiley-Interscience, 1972; Lineare Kontrolltheorie, with H. W. Knobloch, Springer, 1985; Modern Signals and Systems, again with R. Sivan, Prentice-Hall, 1991.) Currently his research is focused on the "polynomial" approach to $\mathscr{H}_{\infty}$-optimization.

Prof. Kwakernaak is a Fellow of the IEEE, has received the IFAC Outstanding Service Award, and is active on various Editorial Boards, of which that of Automatica is the most important. 